\title{
Cue Competition between Animacy and Word Order: Acquisition of Chinese Notional Passives by L2 Learners
}

\author{
Jia Wang1, Caihua $\mathrm{Xu}^{2}$ \\ ${ }^{1}$ Department of Linguistics and Translation, City University of Hong Kong, Hong Kong, China \\ ${ }^{2}$ College of Chinese Language and Culture, Beijing Normal University, Beijing, China \\ Email: jwang245-c@my.cityu.edu.hk
}

Received 20 March 2015; accepted 25 April 2015; published 30 April 2015

Copyright (C) 2015 by authors and Scientific Research Publishing Inc.

This work is licensed under the Creative Commons Attribution International License (CC BY). http://creativecommons.org/licenses/by/4.0/

c) (i) Open Access

\begin{abstract}
Based on the Competition Model (Bates \& MacWhinney, 1978; MacWhinney, 2005; MacWhinney, 2012), the present study investigates $\mathbf{L} 2$ cue strategies in the acquisition of Chinese notional passives by English-speaking and Japanese-speaking learners. Two experiments were conducted to examine both the comprehension and production of Chinese notional passives. The main findings included: 1) L2 learners' acceptability of notional passive increased with improved Chinese proficiency but even advanced learners showed significant difference from Chinese native speakers; 2) L2 learners produced more notional passive sentences than bei-passive sentences and advanced learners showed no difference from Chinese native speakers; 3) Cross-linguistic influence seemed to affect L2 learners' comprehension and production of Chinese notional passives. The results support the universality of animacy cue proposed by Gass (1987) but also suggest that word order and pragmatic factors may affect $\mathrm{L} 2$ learners' cue strategies. The study also evidences the contribution of the input to the development of $\mathrm{L} 2$ cue strategies, which is in line with the predictions of the Competition Model.
\end{abstract}

\section{Keywords}

Chinese Notional Passives, Competition, Cue Strategies, L2 Acquisition, Animacy, Word Order

\section{Introduction}

This study explores how L2 learners of Chinese make use of cues in their acquisition of Chinese notional passive, specifically, the use of animacy cue and word order cue in English-speaking and Japanese-speaking learn-

How to cite this paper: Wang, J., \& Xu, C. H. (2015). Cue Competition between Animacy and Word Order: Acquisition of Chinese Notional Passives by L2 Learners. Open Journal of Modern Linguistics, 5, 213-224.

http://dx.doi.org/10.4236/ojml.2015.52017 
ers of Chinese. By conducting both a comprehension and a production experiment, we examine how the L2 learners' cue strategies develop with increasing Chinese proficiency. Our study also tests whether the learners' L1 backgrounds play a role in their cue strategies.

\subsection{Chinese Notional Passive and Previous Studies}

Passive voice is almost universal in the world's languages but it is represented in various forms. In inflecting languages as well as agglutinating languages, passive construction is usually indicated by compulsory morphological markings on the verb. By contrast, in Chinese, an isolating language, the verb used in an active sentence and a passive one are the same morphologically. Moreover, a wide range of devices are employed to express passive meaning in Chinese (Chao, 1968; Huang, 1999; Lu, 2004; Xiao et al., 2006). According to a corpusbased study by Xiao et al. (2006), Chinese passives fall into two types: one is the marked passive, which makes use of a morpheme, such as bei (the most typical one), jiao, rang; the other is the unmarked passive, which can also refer to notional passives (i.e., the patient is in preverbal position) and lexical passives (i.e., using lexical words such as ai, “suffer”). Examples of marked passives and notional passives are as follows:

1) marked passive: 杯子 被 (他) 打碎作了。

beizi bei (ta) da sui -le

cup marker (he/him) break pieces particle

The cup was broken into pieces (by him).

2) notional passive: 杯子 打 碎 了

beizi da sui $-l e$

cup break pieces particle

The cup was broken into pieces.

In terms of functions, bei passives emphasize the dynamic event itself and the unexpected or undesirable influence on the patient, while notional passives describe the stable and objective state resulted from the action (Xiao et al., 2005; Qu, 2006). The frequency of bei passives and notional passives also vary across different stylistic contexts. Based on a quantitative survey of contemporary Chinese passive constructions, Song et al. (2007) observed that bei passives are more frequently used in formal contexts and notional passives are more frequently used in informal context. The present study is mainly focused on the acquisition of notional passives by Englishspeaking and Japanese-speaking learners of Chinese (L2).

For notional passive sentences in Chinese, the semantic role of the initial noun is the patient of the action denoted by the predicate. In English, the semantic role of the initial noun is also the patient, as exemplified in 3), where "the glass" was acted upon by the action "break". In Japanese, passives fall into two categories: direct passive and indirect passive, as seen in example 4) (cf. Seino \& Tanaka, 2006: 326-328). Similarly, the initial noun "Taro" in direct passive example is also the patient of the action "hit", and "the mother" in the indirect passive example is adversely affected by the event, i.e., "son's death”, so its semantic role can also be considered as "patient” or "affected". Therefore, Chinese notional passives share the same semantic structure as English and Japanese passives.

3) English passive: The glass was broken by John.

4) Japanese passive:

a) Direct passive: Taro-ga Jiro-ni nagur-are-ta.

Taro-NOM Jiro-by hit-Passive-Past "Taro was hit by Jiro"

b) Indirect passive: Sono hahaoya-wa musuko-ni shin-are-ta.

the mother-TOP son-by die-Passive-Past "unfortunately for the mother, the son died"

Despite the similarity, Chinese notional passives are different from passives in English and Japanese in that the verb in Chinese passives remain its bare form whereas the verb is usually changed morphologically in English and Japanese passive constructions. Respectively speaking, in English, "be + done (past participle)” is used in passive sentences, and the verb has to have an additional suffix (except for irregular verbs); in Japanese, the suffix "rareru" should be attached to the stem of vowel-stem verbs and "areru" should be attached to the stem of consonant-stem verbs in passive sentences (Seino \& Tanaka, 2006). It is also worthy to note that Chinese notional passives, without any passive marker, are head-final, structurally parallel with Japanese active sentences (SOV) but quite different from English (SVO). Therefore, it would be interesting to explore how English or Japanese speaking L2 Chinese learners will perform in the comprehension and production of Chinese notional passives. 
Previous studies on the acquisition of L2 Chinese passives have found that many errors seem to be related to notional passives. Li (1996) analyzed the writings of L2 Chinese learners from different L1 backgrounds and found that the most common error was the misuse of the bei marker instead of notional passive or lexical passive. Liu (2000) and Wang (2006) reached the same conclusion through the analysis of the writings by Japanese speaking and Korean speaking learners, respectively. Huang et al. (2007) revealed the same tendency by analyzing English speakers' Chinese writings. A more recent study by Feng (2011) adopted an English-to-Chinese translation task and found that English native speakers tended to correspond to the passive marker bei with the passive marker in English so they translated English passive sentences into Chinese bei sentences instead of notional passive sentences. For example:

5) The gift has been sent to him.

6) bei passive: 礼物 已经 被 寄 给他了。

gift already bei send to him particle

7) notional passive: 礼物 已经 寄 给他了。 gift already send to him particle

In the above example, the notional passive construction is actually more appropriate because the action of "sending a gift" does not have an undesirable effect on the "gift". If, for example, the gift was sent to him by mistake, which is unexpected and undesirable, we could use the bei passive. Therefore, the choice between the notional passive and the bei passive depends on the context.

The studies reviewed above adopt the methodology of error analysis and inform us that the acquisition of Chinese notional passives seems to pose difficulty for L2 learners of Chinese. From an empirical approach, the current study examines the acquisition of Chinese notional passives through controlled experiments within the framework of the Competition Model. The findings of this study will shed light on our understanding of L2 learners' cue strategies in their comprehension and production of such passive constructions.

\subsection{The Competition Model and Second Language Processing}

The Competition Model (henceforth, CM), proposed by Bates and MacWhinney (Bates \& MacWhinney, 1978; 1981; 1989), simulate the procedures learners employ in language acquisition. As a functionalist model, the CM focuses on cross-linguistic variation in the multiple-to-multiple mapping between form and function, so competition will arise when a given form maps onto several functions or a given function maps onto several forms. Learners' task is to discover the particular form-function mappings that characterize the target language. The basic concept of the CM is "cue", represented by various linguistic features, such as stress (phonological cues), verb agreement (morphological cues), preverbal position (word order cues) and noun animacy (semantic cues), and so on. According to Bates and MacWhinney (1989), the primary determinants of cue strength is cue validity, which is the combined product of availability (how often it is present to enact a certain function) and reliability (how often it can be assigned with a certain function when it is present). As stated above, passive voice in Chinese can be represented by notional passives, marked bei passives or lexical passives, so the cue of the passive marker bei is not always available; however, when bei appears in a sentence, it consistently denotes passive meaning. Therefore, passive marker bei in Chinese is low in availability but high in reliability. MacWhinney (2002) has pointed out that availability is more important than reliability for children. We predict that this might be also true for L2 learners especially beginners with limited L2 input.

According to the CM, cues are assigned with different strengths across languages. L2 learners prefer to rely on their L1 settings of cue strength at the beginning of language learning and gradually shift to L2 settings with increasing L2 proficiency (Bates \& MacWhinney, 1987). This has been confirmed in a number of cross-linguistic studies on bilinguals (Harrington, 1987; McDonald \& Heilenman, 1991; Hernandez, Bates, \& Avila, 1994; Su, 2001; Morett \& MacWhinney, 2013). However, there remains controversy over the task of agent identification over unnatural stimuli such as "the logs arechopping the boy (animacy cue in competition with word order cue)". McLaughlin and Harrington (1989) suggested that participants had to resort to a particular problemsolving strategy rather than sentence processing strategy under such situations. Gibson (1992) also commented that the use of ungrammatical stimuli invalidated the results of the experiments based on the CM. Responding to Gibson's criticism, MacWhinney and Bates (1994) argued that results from previous Competition Model experiments did not show sharp discontinuity between grammatical and ungrammatical stimuli.

In view of these disputes, the present study will make an attempt to test the applicability of the CM through grammaticality judgment and sentence completion tasks. In the example 2) above, the noun "beizi (cup)", occu- 
pies the preverbal position, which usually indicates the role of agent, but it is inanimate, so there is a competition between word order and animacy cues. If the word order cue wins, then the noun will be assumed to be the agent and fulfill the action of "breaking something", which is implausible; instead, the cup is usually broken by someone, taking the role of a patient. Therefore, if L2 learners relied on word order cue, they would not accept notional passives with basic world knowledge. By contrast, in marked bei passive, if L2 learners could resort to the cue of the passive marker bei, they would get the meaning of the sentence easily.

Although many studies have confirmed the transfer of L1 processing strategies in L2 acquisition, some studies suggested the existence of a universal cue that is primary to other cues. For example, Gass (1987) found that semantic cues seemed to have a prepotency in language processing. The study found that English-speaking learners of L2 Italian almost did not transfer their L1 syntactic strategies, but Italian-speaking learners of L2 English did transfer their lexical-semantic strategies (animacy cues). Further support comes from Sasaki (1991)'s study of English and Japanese bilinguals and Liu, Bates and Li (1992)'s study of English and Chinese bilinguals. In response to this issue, MacWhinney (1987) argued that an interpretation based on semantic strategy might be a last resort, used when learners fail to find reliable grammatical cues, rather than a universal strategy. Nevertheless, MacWhinney (2008) maintained that animacy cues seemed to be nearly universal because all other things being equal, almost all languages preferred animate subjects. Therefore, more evidence is necessary to test the universality of the animacy cues.

Another issue of our concern is about sentence production. According to MacWhinney (1987), competition among the cues that represent the properties of ideas will arise when ideas and intentions are to be converted into lexical items in production. In a more recent work, MacWhinney (2005) also described sentence production as involving message formulation, lexical activation, morphosyntactic arrangement, and articulator planning. Each step was called an "arena" for competition between items; for example, in the arena of message formulation, different communicative goals compete and winning goals are typically initialized and topicalized. To our knowledge, however, no studies within the framework of the Competition Model have been reported to elicit empirical data on sentence production. The present study will look into the issue of cue strategies in L2 sentence production.

\section{The Present Study}

\subsection{Research Questions}

By examining L2 learners' comprehension and production of Chinese notional passives, this study seeks to investigate Chinese cue strategies of L2 learners. To sum up, we attempt to explore the following questions:

1) Which kind of cue strategies will L2 learners adopt in the comprehension of Chinese notional passives?

2) Which kind of cue strategies will L2 learners adopt in the production of Chinese passives?

3) Will there be cross-linguistic influences in the acquisition of Chinese notional passives by L2 learners?

4) How will L2 learners' acquisition of notional passives develop with increasing Chinese proficiency?

\subsection{Research Method}

Two offline experiments were conducted to explore the above questions through examining the comprehension and production of Chinese notional passives. There was a break of two weeks between the two experiments.

\subsubsection{Experiment One}

\section{Participants}

A total of 111 college students participated in the study. They were recruited from a university in Beijing. They comprised of two main groups: L2 learners of Chinese $(n=91)$ as the experimental group and Chinese native speakers $(\mathrm{CH} ; \mathrm{n}=20)$ as the control group. L2 learners of Chinese were further divided into two groups: English native speakers (EN); Japanese native speakers (JA). L2 learners were from four different levels of Chinese courses which therefore served as the evidence for their relative proficiency. There were 46 EN-subjects: 11 at elementary level, 13 at post-elementary level, 13 at intermediate level, and 9 at advanced level. There were 45 JA-subjects: 13 at elementary level, 10 at post-elementary level, 13 at intermediate level, and 9 at advanced level.

\section{Materials and Procedure}

A grammaticality judgment test was adopted to explore L2 learners' comprehension of notional passives. 
Four types of sentences were included: active sentences $(\mathrm{n}=8)$, notional passives $(\mathrm{n}=8)$, agentless bei-passive $(n=8)$ and non-sentence $(n=24)$. Notional passive sentences are target items; active sentences, with SVO structure, served as a control baseline by which we mean L2 learners are expected to acquire active before passive; agentless bei passives, which have the passive marker, functions as comparison with unmarked notional passives; non-sentences, with wrong word order, served as distractors. All the participants were prompted to rate the sentences on a 1 - 5 scale ( 1 for definitely ungrammatical; 2 for possibly ungrammatical; 3 for not sure; 4 for possibly grammatical; 5 for definitely grammatical). The results were collected as the raw data for subsequent statistical analysis. Therefore, three variables under investigation were sentence type, L1 background, and Chinese proficiency.

Each subject received 48 test stimuli printed in random order on a sheet. The experimenter was present throughout the whole experiment. The sample materials of each sentence type are shown in Table 1.

\subsubsection{Experiment Two}

\section{Participants}

Considering the task difficulty of sentence production, we did not invite participants at the elementary level in Experiment one to participate in experiment two; students at the other 3 levels $(n=67)$ were invited. Another group of native Chinese students $(\mathrm{n}=36)$ participated in the experiment as the control group.

\section{Materials and Procedure}

Paired pictures were used to elicit sentence production. A pilot test was conducted to choose pictures that could successfully elicit notional passives from native Chinese speakers. In order to elicit passive sentences, the subject/topic was designated under each group of pictures. As shown in the following target pictures in Figure 1, “蛋糕 (dan4gao1)”, which means “cake”, was designated as the subject, so the participants had to complete the sentence starting with “蛋糕”. We also used other types of pictures that did not usually elicit passive sentences as distractors, as shown the Figure 1. The order of target items and distractor items were randomized. There were a total of 20 groups of pictures: 10 target pictures aiming to elicit passive sentences and 10 distractors to elicit other types of sentences. The participants were required to complete the sentences according to the given pictures. Pinyin (the Phonetic form of Mandarin Chinese) was acceptable when participants did not know how to write the characters.

\section{Results}

\subsection{Results of Experiment One}

After excluding an outlier whose mean score was beyond two standard derivations in the JA group at elementary level, we obtained the results of the grammaticality judgment task (GJT), as shown in Table 2.

\section{Performance of L2 Chinese Learners}

EN group: ANOVA on the data of L2 learners in the EN group showed a significant main effect of sentence type, $\mathrm{F}(3,126)=390.81, p<0.001$, and every level ranked the four sentence types as follows: Active $>$ Notional passive $>$ Agentless bei-passive $>$ Non-sentence. There was also a significant main effect of L2 proficiency, F(3, $42)=4.39, p<0.01$, but the interaction between sentence type and L2 proficiency was not significant, $\mathrm{F}(9,126)=$ $1.60, p>0.05$. Post-hoc analysis revealed that over the judgment of notional passives and active sentences, the difference between neighboring levels was not significant, $p>0.05$, but over the judgment of agentless bei passives, advanced L2 learners had a significantly higher acceptability than intermediate L2 learners, $p<0.05$. From the mean scores of the GJT, we found that L2 learners across four proficiency levels all accepted active sentence (the scores were 4.66 - 4.92, near 5 "definitely correct"). As for notional passives, L2 learners also tended to consider such a structure acceptable (the average scores were $3.82-4.42$, around 4, "probably correct"), but they were not as determinate as they were toward active sentence. If they had relied on word order cue, the inanimate noun in preverbal position would be regarded as the agent, which is contradictory to common sense (for example, "coffee" cannot perform the action of "drinking" instead it was drunk by someone), and they would reject the notional passive. Therefore, we presume that L2 learners in EN group made use of animacy cue in the comprehension of Chinese notional passive. However, their indeterminacy suggests that they were still sensitive toward word order cue. By contrast, over the judgment of the agentless bei passive, L2 learners showed much more indeterminacy (the average scores were 2.71 - 3.69, around 3, "not sure"), which indicates that the cue of passive marker posed certain difficulty for them. 
Table 1. Examples of test materials in experiment one.

\begin{tabular}{cccc}
\hline Type & Examples & \\
\hline Notional passive & 早饭/做/好/了。 & Breakfast/make/good/-le & The breakfast is ready. \\
Agentless bei-passive & 杯子/被/打/碎/了。 & Cup/hit/broken/-le & The cup was broken. \\
Active sentence & 他/喜欢/北京。 & He/like/Beijing & He likes Beijing. \\
Non-sentence & 老师/他/是。 & Teacher/he/-to be & ? \\
\hline
\end{tabular}

Table 2. Means of GJT (standard derivations in brackets).

\begin{tabular}{|c|c|c|c|c|}
\hline L2 proficiency & L1 background & Agentless bei-sentence & Notional passive & Active sentence \\
\hline \multirow{2}{*}{ Elementary } & EN(11) & $3.10(0.59)$ & $3.82(0.49)$ & $4.66(0.30)$ \\
\hline & $\mathbf{J A}(12)$ & $3.00(0.48)$ & $4.04(0.69)$ & $4.50(0.32)$ \\
\hline \multirow{2}{*}{ Post-elementary } & EN(13) & $3.20(0.94)$ & $4.09(0.32)$ & $4.58(0.54)$ \\
\hline & JA(10) & $3.21(1.22)$ & $3.91(0.57)$ & $4.44(0.60)$ \\
\hline \multirow{2}{*}{ Intermediate } & EN(13) & $2.71(.85)$ & $3.92(0.56)$ & $4.89(0.22)$ \\
\hline & JA(13) & $2.79(.35)$ & $3.98(0.55)$ & $4.70(0.38)$ \\
\hline \multirow[t]{2}{*}{ Advanced } & EN(9) & $3.69(.90)$ & $4.42(0.87)$ & $4.92(0.17)$ \\
\hline & JA(9) & $3.51(.61)$ & $4.57(0.32)$ & $4.87(0.22)$ \\
\hline 1 & CH(20) & $4.81(.30)$ & $4.79(0.29)$ & $4.98(0.06)$ \\
\hline
\end{tabular}

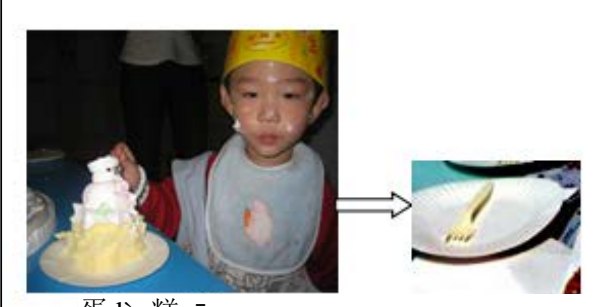

蛋dàn糕gāo

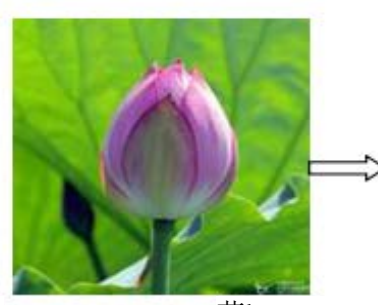

花huā

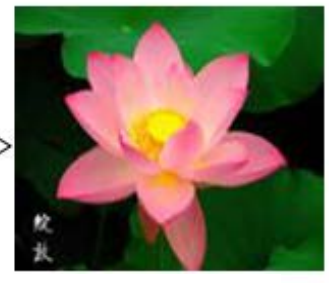

$\circ$

Figure 1. Examples of target pictures (left) and distracters (right) in experiment two.

JA group: ANOVA on the data of L2 learners in the JA group of the four levels showed a significant main effect of sentence type, $\mathrm{F}(3,120)=318.03, p<0.001$, and every level ranked the four sentence types as follows: Active $>$ Notional passive $>$ Agentless bei-passive $>$ Non-sentence. We also found a significant main effect of L2 proficiency, $\mathrm{F}(3,40)=3.00, p<0.05$; the interaction between sentence type and L2 proficiency was not significant, $\mathrm{F}(9,120)=1.87, p>0.05$. Post-hoc analysis did not find significant difference between different proficiency levels on the judgment of notional passive and agentless passive but on the judgment of notional passives, the judgment between advanced level and post-elementary level was marginally significant, $p \approx 0.05$. The mean scores also indicated that L2 learners in the JA group accepted active sentence (the average scores were 4.44 4.87, near 5 "definitely correct") and also notional passive but they showed a little indeterminacy over notional passives (the average scores were 3.91 - 4.57, around 4, "probably correct”). Just as the EN group, L2 learners in the JA group also made use of animacy cue in their comprehension of notional passives and their sensitivity toward word order cue resulted in the indeterminacy. Moreover, also similar to the the EN group, L2 learners in the JA group were also quite uncertain over the grammaticality of the agentless bei passive (the average scores were 2.79 - 3.51, around 3, "not sure"), suggesting that the passive marker bei is also a hamper for the JK group.

Comparison between EN and JA groups: From the analysis of the L2 learners' performances above, we found L2 learners in the EN group and the JA group were quite similar in that they made use of animacy cue in the comprehension of Chinese notional passives but both groups were a little sensitive to word order cue. Moreover, both groups showed indeterminacy in the cue of the passive marker bei. To confirm our observation, we conducted a one-way ANOVA on the data from the two groups. The results indicated that both groups in- 
deed showed no significant difference in the acceptability of notional passives from elementary to advanced proficiency $(\mathrm{F}(1,22)=0.79, p>0.05 ; \mathrm{F}(1,22)=0.93, p>0.05 ; \mathrm{F}(1,25)=0.08, p>0.05 ; \mathrm{F}(1,17)=0.24, p>$ 0.05). Similarly, the EN and JA groups at all proficiency levels showed no significant difference in the judgment of the agentless bei passive $(\mathrm{F}(1,22)=0.20, p>0.05 ; \mathrm{F}(1,22)=0.003, p>0.05 ; \mathrm{F}(1,25)=0.17, p>0.05$; $\mathrm{F}(1,17)=0.26, p>0.05)$. These findings suggest that English-speaking and Japanese-speaking learners had similar performance in the comprehension of Chinese notional passives and agentless bei passives.

\section{Comparison between $\mathrm{L} 2$ Chinese learners and Chinese Native Speakers}

EN and CH: A one-way ANOVA analysis was conducted on the data of the EN group and native Chinese speakers, as illustrated in Figure 2. It was found that L2 learners from elementary level to intermediate level all had a significantly lower acceptability of notional passives than natives $(\mathrm{F}(1,30)=48.97, p<0.001 ; \mathrm{F}(1,32)=$ 42.03, $p<0.001 ; \mathrm{F}(1,32)=33.83, p<0.001)$, but the difference between the EN group and natives was not significant at the advanced level, $\mathrm{F}(1,28)=3.03, p>0.05$, which indicates that with increased proficiency, L2 learners in EN group became native-like in the comprehension of notional passive and their use of animacy cue. Over the judgment of active sentence, it is also not until advanced level that L2 learners showed no significant difference from natives, $\mathrm{F}(1,28)=2.41, p>0.05$. However, over the judgment of agentless bei passives, L2 learners in the EN group across all proficiency levels showed significantly lower acceptability than natives, ( $\mathrm{F}(1$, $30)=116.48, p<0.001 ; \mathrm{F}(1,32)=51.54, p<0.001 ; \mathrm{F}(1,32)=198.94, p<0.001 ; \mathrm{F}(1,28)=25.72, p<0.001)$. This lends more support to previous analysis of their difficulty in the acquisition of the passive marker bei.

JA and CH: A one-way ANOVA analysis was also conducted on the data from the JA and Chinese native groups, as illustrated in Figure 3. Results indicated that the JA group had significantly lower acceptability of notional passives than native Chinese from elementary to intermediate level $(\mathrm{F}(1,31)=18.34, p<0.001$; $\mathrm{F}(1$, $29)=32.17, p<0.001 ; \mathrm{F}(1,32)=37.98, p<0.001)$, however, there was no significant difference between advanced JA and natives, $F(1,28)=3.35, p>0.05$. Over the judgment of active sentences, the development pattern was the same: L2 learners had significantly lower acceptability than native Chinese $(\mathrm{F}(1,31)=43.57, p<$ $0.001 ; \mathrm{F}(1,29)=16.58, p<0.001 ; \mathrm{F}(1,32)=22.30, p<0.001 ; \mathrm{F}(1,28)=4.24, p<0.05)$. Similarly, L2 learners had significantly lower acceptability of agentless bei passives than natives across all proficiency levels, (F(1, 31) $=175.72, p<0.001 ; \mathrm{F}(1,29)=31.52, p<0.001 ; \mathrm{F}(1,32)=320.43, p<0.001 ; \mathrm{F}(1,28)=62.54, p<0.001)$, which also confirmed our analysis above that L2 learners in the JA group also had difficulty in acquiring the passive marker bei.

To summarize so far, the results from Experiment one demonstrated that L2 Chinese learners from both EN and JA group could make use of animacy cue in their comprehension of notional passive but this was influenced by their sensitivity toward word order cue; with increasing Chinese proficiency, both EN and JA became native-like in their use of animacy cue. We also found that L2 learners have difficulty in acquiring the cue of the passive marker bei and even at higher proficiency their acquisition was significantly different from native Chinese speakers. Then how do L2 learners make use of cues in production? Let's turn to the results from Experiment two.

\subsection{Results of Experiment Two}

Recall that an inanimate noun, such as “蛋糕 (cake)”, was designated as the subject under each group of pictures in Experiment two. As expected, most of the sentences produced were passive sentences, which could be categorized into 3 types: notional passives, bei-passives, and others. The percentage of each type was demonstrated in Figure 4. Examples of each type are as follows:

8) Notional passive: 蛋糕吃(完)了。(The cake was eaten up.)

9) Bei passive: 蛋糕被(孩子)吃完了。(The cake was eaten up (by the boy)).

10) Others: 蛋糕沒有了。(There is no cake left.)

First, let's look at the results from the control group. There were nearly twice the number of notional passives (61\%) as for bei-passives (31\%), indicating that native Chinese speakers preferred notional passives to bei passives in the given context of the present study. Similarly, the results of L2 learners showed that both groups at every proficiency level all preferred notional passives to bei passives and they even showed stronger reliance on the use of notional passives compared to native speakers, which is suggestive of their use of animacy cue. Moreover, L2 learners produced much less bei passives than native Chinese, but at the Advanced level, the ratio of notional passives dropped a little and the ratio of bei-passives increased (from less than 5\% to around 15\%), which indicates that the use of the passive marker bei is difficult for L2 learners but their acquisition of this cue 


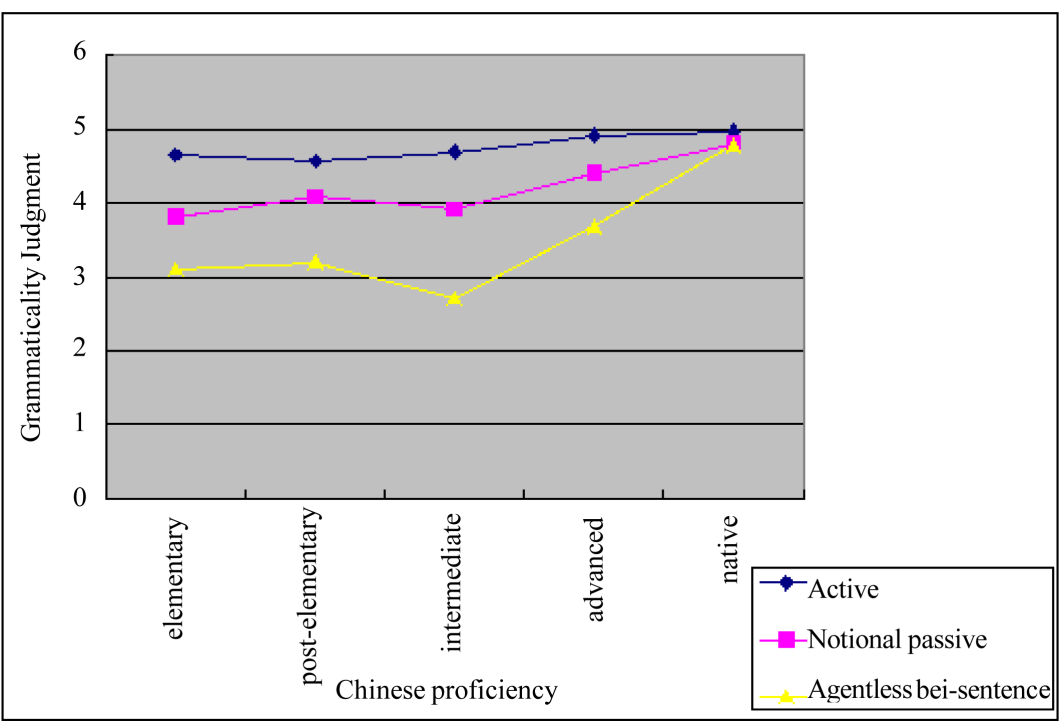

Figure 2. Comparison between L2 learners in EN group and Chinese native speakers.

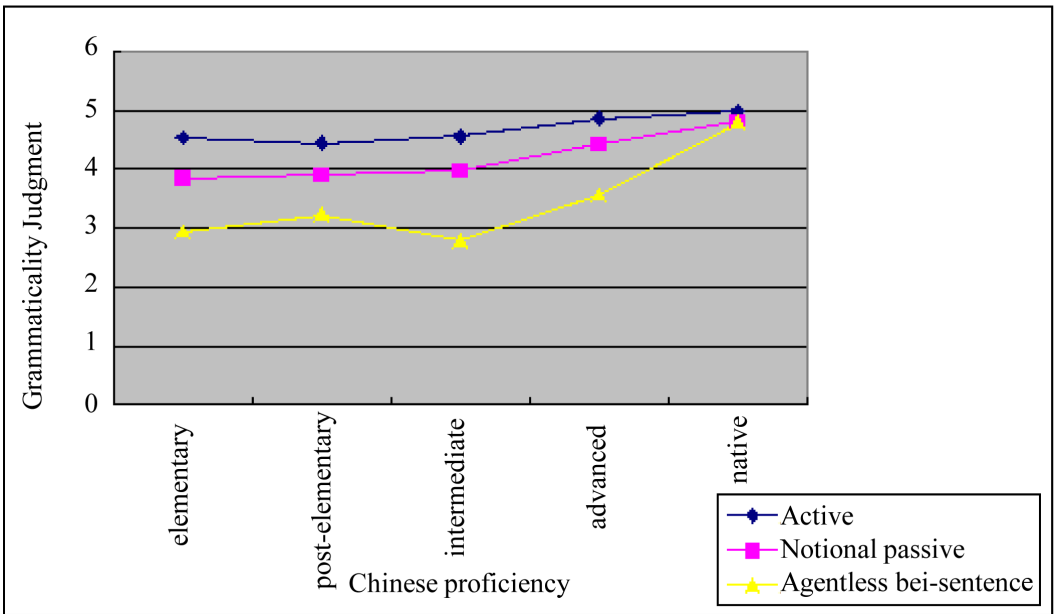

Figure 3. Comparison between L2 learners in JA group and Chinese native speakers.

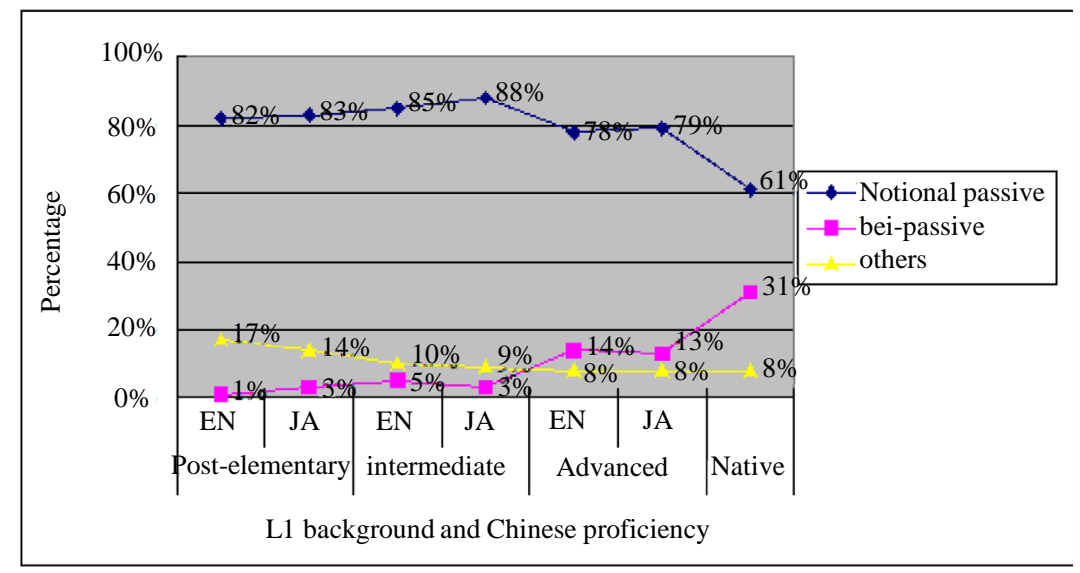

Figure 4. Results of sentence production in experiment two. 
improves with increasing Chinese proficiency. The results of Experiment two are compatible with our findings in Experiment one: L2 learners could make use of animacy cue and acquire notional passives quite easily but they had difficulty in acquiring the cue of the passive marker bei.

\section{Discussion}

This study investigated L2 learners' cue strategies in the comprehension and production of Chinese notional passives. Two offline experiments were conducted: Experiment one examined how L2 learners with different Chinese proficiencies (4 levels) and different L1 backgrounds (English and Japanese) interpreted Chinese notional passive. Experiment two explored whether L2 learners could produce Chinese notional passive in given contexts. It was found that L2 learners could make use of animacy cue in their comprehension of notional passives and their performance became native-like with increased Chinese proficiency. In production, L2 learners showed even stronger reliance on the use of notional passives compared to native Chinese speakers. By contrast, L2 learners showed difficulty in their use of the passive marker bei in the comprehension and accordingly they produced quite a limited number of bei passive sentences.

\subsection{The Universality of Animacy Cue}

Our results showed that animacy cue is accessible to L2 learners from the very beginning (elementary level), evidenced by their high acceptability of notional passives. This lends support to Gass (1987)'s claim that animacy cue is universal and also echoes the findings of Sasaki (1991) that English-speaking learners of Japanese tended to drop L1 word order cue and resorted to L2 animacy cue. We consented to MacWhinney (2008)'s argument that since nearly all languages preferred animate subjects under normal circumstances, animacy cue is nearly universal. In Chinese notional passives, the subject position is occupied by an inanimate noun, such as “蛋糕 (the cake)”, and the verb-complement phrase, such as “吃完 (eat up)”, which obviously acts upon the initial noun but the actor (agent) is not told. It turned out thatL2 learners made use of animacy cue and perceived the meaning of the notional passive correctly; otherwise, if they had used word order cue and regarded the inanimate noun as the subject (agent), they would not have accepted notional passive. As pointed out in MacWhinney (2002), children might have difficulty in understanding passive but by the age of four or five, they would have no problem by turning to cues such as "by", "past participle", and etc. In the case of notional passives, although there is neither a passive marker nor morphological inflection on the verb, adult L2 learners could also make use of animacy cue to comprehend the sentence with their basic world knowledge.

\subsection{Effects of Word Order and Pragmatic Cues}

Although L2 learners made use of animacy cue and accepted notional passives, they still showed indeterminacy to some extent compared with native Chinese, which can be seen from the result that their acceptability of notional passive was significantly lower than natives before they reached advanced proficiency. We presume that this may be due to their sensitivity toward word order cue. As is shown from the results in Experiment one, L2 learners acquired active sentences quite early and easily, which provides evidence for their strong awareness of Chinese basic word order SVO. Therefore, when confronted with a notional passive sentence with the word order OV, they might think that the subject is missing or the object should appear after the verb. Within the framework of the Competition Model, there exists competition between animacy cue and word order cue in the comprehension of Chinese notional passives by L2 learners. Even though animacy cue won out at last, word order cue still affected L2 learners' comprehension of notional passives.

In sentence production, L2 learners relied on notional passives instead of the marked bei passive. Compared with Chinese native speakers, they produced much less bei passives. This seems to be inconsistent with previous findings that L2 learners tend to overgeneralize passive marker bei (Li, 1996; etc.). One possible reason, we speculate, is that L2 learners are oversensitive to the restriction of the Chinese bei passive that bei is usually used in undesirable contexts, which is often stressed during the instruction of passive structures. In the present study, the contexts provided by the pictures were neutral, such as a boy ate up the whole piece of cake, a girl drank up the coffee, and etc. Therefore, L2 learners may avoid using the bei passive in a non-negative context. It was found that L2 learners across four proficiency levels produced about $80 \%$ of notional passives but only about $5 \%$ of bei passives at intermediate proficiency; even when they reached advanced proficiency, there was still only 13\% - 14\% bei passive. By contrast, native speakers produced almost a third of bei passives (31\%). 
Recall that L2 learners showed a high degree of indeterminacy in accepting agentless bei passive in comprehension. By scrutinizing the test materials and the data, we found that L2 learners had a higher acceptability of bei passives that bear a negative meaning, such as “钱包被偷走了 (The purse was stolen)”, the average judgment of which was 4.20 by the English-speaking group and 4.12 by the Japanese-speaking group, but they tended to reject those with neutral meaning, such as “车被开走了 (The car was driven away)", the average judgment of which was 2.65 by English-speaking group and 2.72 by Japanese-speaking group. In a study by Wu and Zhou (2005), a typical context was used to elicit bei passive from L2 learner of Chinese, that is, "someone was hit by a car", which is negative under normal circumstances. It was found that L2 learners produced a high percentage of bei passive, indicating L2 learners' sensitivity to the pragmatic factors. Comparing our study with Wu and Zhou's, we may also speculate that one possible reason why animacy cue could win over the cue of passive marker bei in production is that L2 learners were quite aware of the pragmatic cue: undesirable context.

\subsection{Input and Development of L2 Cue Strategy}

The role of input cannot be underestimated in second language acquisition. We found that L2 learners' acquisition of notional passives was a slow and gradual process. With increasing Chinese proficiency, L2 learners became native-like in their comprehension of notional passives at the advanced proficiency, which indicated that they made better use of animacy cue and were affected less by word order. The Competition Model states that what control language learning are the distributional properties of the input, and cues with high reliability and availability are acquired first (MacWhinney, 2002). As mentioned above, notional passives are frequently used in Chinese, especially in informal spoken contexts. Besides, it has been found that animacy cue is the strongest cue second to the passive marker bei (Li et al., 1993). As for word order cue, it is not quite reliable in that Chinese varies in SVO, OSV and SOV. Therefore, with more exposure, L2 learners could make better use of animacy cue and became less sensitive to the word order cue.

In addition, $\mathrm{Li}$, Bates, and MacWhinney (1993) also found that the passive marker bei was the strongest cue for native Chinese speakers. It was explained that native Chinese had received enough input of bei sentences even though they are not so frequently used in Chinese. However, for L2 learners, the low availability of bei sentences may lead to their persistent difficulty in acquiring the passive marker bei even until advanced proficiency, apart from the influence of pragmatic factors we analyzed above.

\subsection{L1 Transfer on Cue Strategies}

The results of the present study showed there were no significant differences between the two groups: English speaking learners and Japanese speaking learners, which seems to indicate that there is no L1 transfer on the cue strategies by L2 learners. However, we observed that L2 learners from both groups were affected by word order cue in their comprehension of notional passive before advanced proficiency as discussed. Apart from intra-linguistic interference from L2 Chinese analyzed above, there might also be inter-linguistic interference, that is, L1 transfer. For English-speaking learners, they might transfer their L1 syntax-based strategy such as word order cue or morphological cue (inflections) into their comprehension of notional passives: notional passives have OV order but no morphological inflections are required on the noun or the verb; therefore, L1-English learners showed indeterminacy over the grammaticality of notional passive before they reached advanced proficiency. For Japanese-speaking learners, unexpectedly, they did not show any advantage over L1-English learners since their L1 cue strategy is semantic-based (Sasaki, 1991). We assume that L1 transfer, if it occurred, was counteracted by the inter-linguistic interference from Chinese word order cue. As seen from their high acceptability of Chinese active sentence, L1-Japanese learners were well aware of the main word order of Chinese SVO, which differentiates from their L1 word order SOV. As predicted by the Competition Model, L2 learners start with L1 cue strategies in their L2 processing, and this has been confirmed in many cross-linguistic studies based on the model (Harrington, 1987; Su, 2001; McDonald \& Heilenman, 1991; Hernandez, Bates, \& Avila, 1994). Although the present study failed to find a strong effect of L1 transfer, it offered more evidence for the universality of animacy effect, which may overwhelm the cross-linguistic influence.

\section{Conclusion}

The present study finds that L2 learners of Chinese can make use of animacy cue in their acquisition of Chinese notional passives, thus providing more evidence for the universality of semantic cue. However, we also find that 
the cue strategies are also affected by word order, pragmatic factors, L1 transfer and most importantly, L2 input. It must be pointed out that this study adopts an offline methodology without recording the response time so a more vivid and nuanced picture of L2 language processing is not demonstrated. Despite the limitation, the findings of our study display a comprehensive analysis of L2 learners' cue strategies in the comprehension and production of Chinese notional passives. Research in the future may replicate the present study with online tasks so as to further explore factors that may affect L2 cue strategies in second language acquisition.

\section{Acknowledgements}

We appreciate the editors and the anonymous reviewers for their hard work and valuable comments to enhance this paper. Thanks go to Dr. CHAN Yuet Hung Cecilia for her valuable suggestions during the preparation of the manuscript. Thank Daniel Lee and Phuong Nguyen for their help in revising the paper. All remaining errors, if any, remain our own.

\section{References}

Bates, E., \& MacWhinney, B. (1978). Competition, Variation and Language Learning. In B. MacWhinney (Ed.), Mechanisms of Language Acquisition (pp. 157-194). Hillsdale, NJ: Erbaum.

Bates, E., \& MacWhinney, B. (1981). Second Language Acquisition from a Functionalist Perspective: Pragmatic, Semantic, and Perceptual Strategies. In H. Winitz (Ed.), Annals of the New York Academy of Sciences Conference on Native and Foreign Language Acquisition (pp. 190-214). New York: New York Academy Press.

Bates, E. A., \& MacWhinney, B. (1989). Functionalism and the Competition Model. In B. MacWhinney, \& E. Bates (Eds.), The Cross Linguistic Study of Sentence Processing (pp. 3-76). New York: CUP.

Chao, Y.-R. (1968). A Grammar of Spoken Chinese. Berkeley: University of California Press.

Feng, J. (2011). Analysis of the Issue of Generalization in the Acquisition of Chinese Notional Passive by English Native Speakers. Journal of Language and Literature Studies, 4, 163-164.

Gass, S. M. (1987). The Resolution of Conflicts among Competing Systems: A Bidirectional Perspective. Applied Psycholinguistics, 8, 329-350.

Gibson, E. (1992). On the Adequacy of the Competition Model. Language, 68, 812-830.

Harrington, M. (1987). Processing Transfer: Language-Specific Processing Strategies as a Source of Interlanguage Variation. Applied Psycholinguistics, 8, 351-377.

Hernandez, A. E., Bates, E. A., \& Avila, L. X. (1994). On-Line Sentence Interpretation in Spanish-English Bilinguals: What Does It Mean to Be "In Between"? Applied Psycholinguistics, 15, 417-446.

Huang, C. T. J. (1999). Chinese Passives in Comparative Perspective. Tsinghua Journal of Chinese Studies, 29, 423-509.

Huang, Y., Yang, S., Gao, L., \& Cui, X. (2007). The L2 Acquisition of the Chinese Bèi-Construction. Chinese Teaching in the World, 80, 76-90.

Li, D. (1996). Waiguoren xuehanyu yufa pianwu fenxi (Error Analysis of the Grammar of Foreigners Learning Chinese). Beijing: Beijing Language and Culture University Press.

Liu, H., Bates, E., \& Li, P. (1992). Sentence Interpretation in Bilingual Speakers of English and Chinese. Applied Psycholinguistics, 13, 451-484. http://dx.doi.org/10.1017/S0142716400005762

Lu, J. M. (2004). Some Issues of Passive Sentences of Mandarin Chinese. Chinese Linguistics, 8, 9-15.

MacWhinney, B. (2005). Extending the Competition Model. International Journal of Bilingualism, 9, 69-84. http://dx.doi.org/10.1177/13670069050090010501

MacWhinney, B. (2002). The Competition Model: The Input, the Context, and the Brain. Pittsburgh: Department of Psychology, Carnegie Mellon University, Paper 219.

http://repository.cmu.edu/cgi/viewcontent.cgi?article=1214\&context=psychology

MacWhinney, B. (2012). The Logic of the Unified Model. In Handbook of Second Language Acquisition (pp. 211-227). London: Routledge.

MacWhinney, B. (2008). A Unified Model. In N. C. Ellis, \& P. Robinson (Eds.), Handbook of Cognitive Linguistics and Second Language Acquisition (pp. 341-372). New York: Erlbaum.

MacWhinney, B., \& Bates, E. (1994). The Competition Model and UG. Pittsburgh, PA: Department of Psychology, Research Showcase at Carnegie Mellon University.

McDonald, J. L., \& Heilenman, L. K. (1991). Determinants of Cue Strength in Adult First and Second Language Speakers of 
French. Applied Psycholinguistics, 12, 313-348. http://dx.doi.org/10.1017/S0142716400009255

McLaughlin, B., \& Harrington, M. (1989). Second-Language Acquisition. Annual Review of Applied Linguistics, 10, 122134. http://dx.doi.org/10.1017/S0267190500001240

Morett, L. M., \& MacWhinney, B. (2013). Syntactic Transfer in English-Speaking Spanish Learners. Bilingualism: Language and Cognition, 16, 132-151. http://dx.doi.org/10.1017/S1366728912000107

Qu, C. X. (2006). Chinese Discourse Grammar. Beijing: Beijing Language and Culture University Press.

Sasaki, Y. (1991). English and Japanese Interlanguage Comprehension Strategies: An Analysis Based on the Competition Model. Applied Psycholinguistics, 12, 47-73. http://dx.doi.org/10.1017/S0142716400009371

Seino, T., \& Tanaka, S. (2006). The "Passive” Voice in Japanese and German: Argument Reduction versus Argument Extension. Linguistics, 44, 319-342. http://dx.doi.org/10.1515/LING.2006.012

Song, W. H., Luo, Z. J., \& Yu, J. C. (2007). A Quantitative Analysis of the Occurrence Ratio of Agent in Contemporary Chinese Passive Constructions. Studies of the Chinese Language, 02, 113-124.

Su, I. R. (2001). Transfer of Sentence Processing Strategies: A Comparison of L2 Learners of Chinese and English. Applied Psycholinguistics, 22, 83-112. http://dx.doi.org/10.1017/S0142716401001059

Wu, M. J., \& Zhou, X. B. (2005). The Comparison of Learning Difficulty on Chinese Bei-Sentence and Passive Sentence in Meaning. Chinese Language Learning, 01, 62-65.

Xiao, R., McEnery, T., \& Qian, Y. (2006). Passive Constructions in English and Chinese: A Corpus-Based Contrastive Study. Languages in Contrast, 6, 109-149. http://dx.doi.org/10.1075/lic.6.1.05xia

Wang, Z. L. (2006). Xiandai hanyu beidong biaoshu litihua yanjiu (A Comprehensive Study on Chinese Passive). Dalian: Liaoning Normal University Press. 